\title{
Measurement of human fetal blood flow
}

\author{
STURLA H EIK-NES, ALF O BRUBAKK, MAGNAR K ULSTEIN
}

\section{Summary and conclusions}

Real-time B-mode ultrasonography was combined with a pulsed Doppler ultrasound technique for transcutaneous measurement of human fetal blood flow in the aorta and intra-abdominal part of the umbilical vein. The target vessel was located and its diameter measured in the two-dimensional real-time image. The pulsed Doppler transducer was attached to the real-time transducer at a fixed angle. By processing the Doppler shift signals the instrument estimated the mean and maximum blood velocities and the integral under the velocity curves. This permitted calculation of the blood flow. The method was applied to 26 fetuses in normal late pregnancies. Mean blood flow in the descending part of the fetal aorta based on maximum velocity was $191 \mathrm{ml} / \mathrm{kg} / \mathrm{min}$. Mean flow in the intra-abdominal part of the umbilical vein was $110 \mathrm{ml} / \mathrm{kg} / \mathrm{min}$.

This method of measurement is non-invasive and opens new perspectives in studying fetal haemodynamics.

\section{Introduction}

Blood circulation in fetal animals has been extensively studied by using invasive methods. Circulatory studies in the human fetus require non-invasive methods, which at present do not exist. Therefore, information on human fetal circulation is scarce and based mainly on measurements made in early abortions $\mathrm{s}^{2}$ and neonates immediately after delivery. ${ }^{34}$

In 1977 a method was reported in which B-mode ultrasonography and continuous Doppler ultrasound were combined to obtain signals from the umbilical cord in utero. ${ }^{5}$ Recently, Gill and Kossof ${ }^{6}$ showed how flow in the umbilical vein may be measured with pulsed Doppler. ultrasound. By using real-time ultrasonography detailed fetal anatomy may be seen. The resolution of commercially available real-time ultrasound equipment is sufficient to give a clear image of fetal vessels such as the aorta, vena cava, intra-abdominal part of the umbilical vein, and umbilical cord. Transcutaneous measurement of blood velocity has been performed in adults by using continuous ultrasound and the Doppler principle. ${ }^{7}$ By combining real-time ultrasonography and pulsed Doppler ultrasound we measured blood flow within human vessels.

\section{Materials and methods}

We used a multilinear real-time scanner (ADR, Tempe, Arizona) with a $3.5 \mathrm{MHz}$ transducer to visualise the fetal aorta and intraabdominal part of the umbilical vein. Fetal blood velocity was measured with a $2 \mathrm{MHz}$ pulsed Doppler instrument (PEDOF, SINTEF, Norwegian Institute of Technology, Trondheim, Norway) ${ }^{8}$ with an unfocused transducer (diameter $1.2 \mathrm{~cm}$ ). This instrument emits coherent ultrasound pulses at a frequency of $2 \mathrm{MHz}$ with a

Department of Obstetrics and Gynaecology, Central Hospital, Aalesund, Norway

STURLA H EIK-NES, MD, research fellow

University of Trondheim, Trondheim, Norway

ALF O BRUBAKK, MD, lecturer, institute of clinical physiology MAGNAR K ULSTEIN, MD, professor, department of obstetrics and gynaecology duration of $10 \mu \mathrm{s}$ and repetitions of 6.5 and $9.75 \mathrm{kHz}$. By using the sample-volume control of this instrument the examiner can determine the depth at which blood velocity is to be measured. Velocities up to $1.7 \mathrm{~m} / \mathrm{s}$ can be estimated down to a depth of $6.0 \mathrm{~cm}$, and velocities up to $1.0 \mathrm{~m} / \mathrm{s}$ between 6 and $10 \mathrm{~cm}$. The reflected signal is led through an estimator of maximum and mean blood velocity, which produces analogue voltages proportional to these two velocities. The instrument is also equipped with a simple integrator circuit, which calculates the area under the velocity curve.

The fetal aorta and the intra-abdominal part of the umbilical vein were located with a real-time B-mode scanner. The transducer was moved until the longitudinal axis of the vessel was parallel to the transducer. The Doppler transducer was attached to the real-time transducer at a fixed angle (fig 1). The distance between the real-time

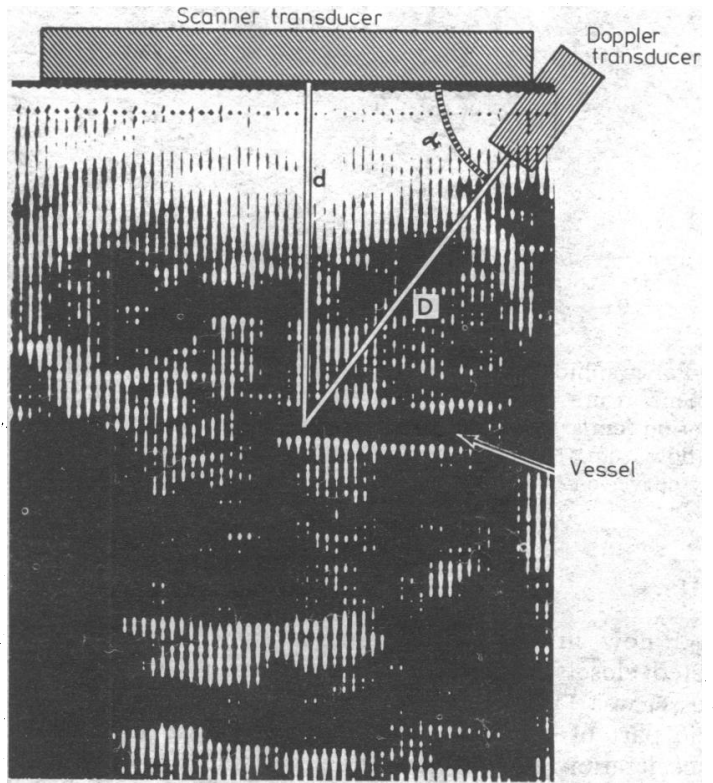

FIG 1-Schematic diagram of method of measuring fetal blood flow, showing real-time image of transverse section of fetal abdomen with intra-abdominal part of umbilical vein.

$D=$ Distance from Doppler transducer to vessel; $d=$ distance from realtime transducer to vessel; $\alpha=$ fixed angle between real-time and Doppler transducers.

transducer and the vessel, and the diameter of the vessel, were measured on the B-mode screen. Owing to interference the two instruments could not be used simultaneously. Thus when the vessel was located properly the B-mode scanner was turned off and the Doppler velocity meter turned on. The sample-volume control of the Doppler velocity meter was set at the depth determined from the B-scan measurements, thus placing the sample volume within the vessel of interest. The four output signals of the Doppler instrumentthat is, mean velocity, maximum velocity, integral under the velocity curves, and derivative of the velocity curve (that is, acceleration)were registered on a polygraph (fig 2). The blood flow, $Q$, was calculated from the blood velocity according to the formula $\mathrm{Q}=\mathrm{V} \times \mathrm{A} / \cos \alpha$, where $\mathrm{V}$ is the mean or maximum velocity, $\mathrm{A}$ the cross-sectional area of the vessel, and $\alpha$ the angle between the vessel and the Doppler ultrasonic beam.

We applied this method to 26 women with uncomplicated pregnancies. Gestational age ranged from 32 to 41 weeks. Fetal weight at the time of measurement ranged from 1780 to $4330 \mathrm{~g}$. In 18 pregnancies, in which delivery occurred more than one week after the flow was measured, the fetal weight was estimated by ultrasound measurement of fetal biparietal diameter and abdominal transverse 
diameter. ${ }^{9}$ The weights of the neonates were appropriate for gestational age.

The calculation of flow in the fetal aorta was based on the maximum blood velocity registered over 10 heart beats; in the intra-abdominal part of the umbilical vein the calculation was based on the mean blood velocity registered over $15 \mathrm{~s}$. The reproducibility of the method was tested in five patients, in whom flow in the umbilical vein was measured twice within one hour.

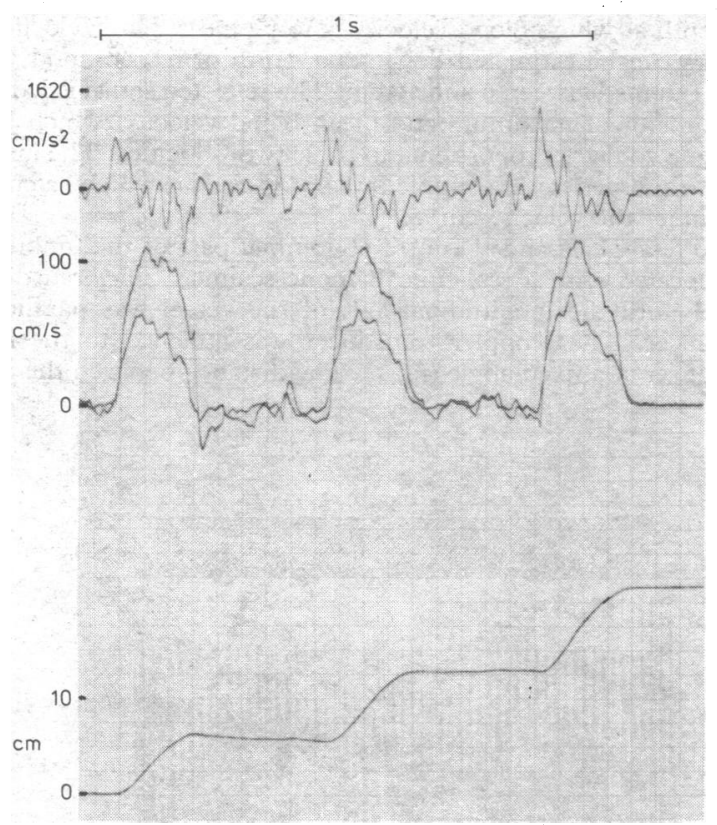

FIG 2-Polygraphic record of the four output signals obtained with Doppler instrument from human fetal aorta. Upper tracing shows blood-flow acceleration $\left(\mathrm{cm} / \mathrm{s}^{2}\right)$; middle tracings show maximum and mean yelocities of blood flow $(\mathrm{cm} / \mathrm{s})$; and lower tracing shows integral under maximum velocity curve $(\mathrm{cm})$.

\section{Results}

Blood flow in the intra-abdominal part of the umbilical vein correlated closely with fetal weight. Mean ( \pm SE of mean) flow in this vessel was $110 \pm 5.8 \mathrm{ml} / \mathrm{kg} / \mathrm{min}(\mathrm{n}=20)$. Mean blood flow in the thoracic part of the fetal aorta was $191 \pm 12 \cdot 2 \mathrm{ml} / \mathrm{kg} / \mathrm{min}(\mathrm{n}=26)$. The acceleration of the blood flow was fairly steady with a mean value of $2927 \pm 65 \cdot 7 \mathrm{~cm} / \mathrm{s}^{2} \quad(n=26)$. In all of the reproducibility tests the difference between two measurements did not exceed $10 \%$.

\section{Discussion}

The major problems when measuring blood flow transcutaneously by using a Doppler technique have been the angle between the Doppler transducer and the vessel, the dimension of the vessel, and the velocity profile within the vessel. ${ }^{10}$ In this study the problem of angling was solved by combining the real-time transducer and the Doppler transducer (fig 1), while the modern ultrasound B-mode equipment permitted measurement of the vessel dimension.

The flow in a vessel is proportional to the mean velocity over the cross-section. To obtain a true mean value of the velocity the vessel must be located completely within the range of the sample volume of the pulsed Doppler instrument, and the ultrasonic field must be homogeneous. These criteria were fulfilled in this study. When aortic flow is being measured, however, the interference from other vessels may influence the estimate of the mean velocity. Therefore, we used the estimated maximum blood velocity to calculate flow in the aorta, assuming that the velocity profile in this vessel was flat. This assumption may have resulted in a slightly overestimated aortic flow.

Dawes ${ }^{11}$ calculated the minimum blood flow needed in the umbilical vein of the human fetus to be $90 \mathrm{ml} / \mathrm{kg} / \mathrm{min}$. This calculation was based on consumption of oxygen. By using an ultrasound technique Gill and Kossof ${ }^{6}$ found flow in the umbilical vein to be $105 \mathrm{ml} / \mathrm{kg} / \mathrm{min}$, which is extremely close to our result. Thus the results obtained from both studies exceed the calculated minimum flow.

Owing to the inaccessibility of the human fetus in situ no data on blood flow in the descending aorta of the human fetus at term are available. The data on fetal circulatory physiology obtained from animal studies cannot be applied unreservedly to the human fetus because of physiological and anatomical differences and because invasive methods for studying blood flow may possibly interfere with the flow per se. ${ }^{12}$

This transcutaneous pulsed Doppler ultrasonic technique is a non-invasive method of measuring blood flow in the human fetus without disturbing the flow in the vessel. The method is simple and uses only commercially available equipment. Applying this method to a study of fetal haemodynamics appears feasible.

This study was financed by grants from Aalesund Central Hospital and the University of Trondheim Medical School, Norway. The equipment used was provided by Kranzbühler and Son, Solingen, Germany, and Nycotron, Drammen, Norway. We acknowledge the valuable advice and help given by Kjell Kristoffersen, Norwegian Institute of Technology, Trondheim; Karel Maršál, department of obstetrics and gynaecology, University of Lund, Malmö, Sweden; and Olav Bakken, Nycotron, Drammen.

Requests for reprints should be addressed to Dr S H Eik-Nes; Aalesund Central Hospital, N-6017 Aasestranda, Norway.

\section{References}

1 Assali NS, Rauramo L, Peltonen T. Measurement of uterine blood flow and uterine metabolism. Am $\mathcal{F}$ Obstet Gynecol 1960;79:86-98.

2 Morris JA, Hustead RF, Robinson RG, Haswell GL. Measurement of fetoplacental blood volume in the human previable fetus. Am $\mathcal{F}$ Obstet Gynecol 1974;118:927-34.

3 Stembera ZK, Hodr J, Janda J. Umbilical blood flow in healthy newborn infants during the first minute after birth. Am $\mathcal{F}$ Obstet Gynecol 1965; $91: 568-74$.

4 McCallum WD. Thermodilution measurement of human umbilical blood flow at delivery. Am ₹ Obstet Gynecol 1977;127:491-6.

5 Fitzgerald DE, Drumm JE. Non-invasive measurement of human fetal circulation using ultrasound: a new method. Br Med f 1977;ii:1450-1.

${ }^{6}$ Gill RW, Kossof G. Quantitative blood flow measurement in deep-lying vessels. In: Chef $\mathrm{R}$, ed. Real time ultrasound in perinatal medicine. Basle: S Karger, 1977:139-41.

7 Satomura S. Study of the flow pattern in arteries by ultrasonics. $\mathcal{F}$ Acoust Soc fap 1959;15:151-8.

8 Angelsen BAJ, Brubakk AO. Transcutaneous measurement of blood flow velocity in the human aorta. Cardiovas Res 1976;10:368-79.

${ }^{9}$ Eik-Nes SH, Grottum P. Estimation of fetal weight by ultrasound measurement. In: Schmidt E, Dudenhausen JW, eds. Proceedings of the 1 st international Berlin meeting on perinatal medicine. Berlin. Stuttgart: Georg Thieme Verlag (in press).

10 Peronneau P. Pulsed Doppler ultrasonic flowmeter and flow pattern analysis. In: Roberts VC. Blood flow measurement. London: Sector Publishing Limited, 1972:24-8.

11 Dawes GS. Fetal and neonatal physiology. Chicago: Yearbook Medical Publishers Inc, 1968:76.

12 Lind J. Human fetal and neonatal circulation. Eur $\mathcal{F}$ Cardiol 1977;5/3: 265-81.

(Accepted 8 November 1979)

ONE HUNDRED YEARS AGO Dr Emmet (Principles and Practice of Gynaecology) describes the following method of treatment of procidentia uteri as being practised successfully by a shrewd border physician. His practice was almost exclusively confined to the negroes. A case was cured in ten days. The woman was placed in a swing, suspended to a beam, in the knee and chest position. This was maintained for ten days, during which time the vagina was kept filled with a strong decoction of oak-bark, which was changed every day by means of a syringe. With a properly padded swing there was no difficulty, as the woman slept all the time, and was disturbed only to receive her food or to answer a call of nature. The principles of treatment were undoubtedly correct, although the method be unsuitable in other races. (British Medical fournal, 1880.) 